\title{
Successful TQM Implementation in Sri Lankan Public Hospitals
}

\author{
Samantha Padmasiri KALUARACHCHI \\ Graduate School of Business Administration, Hosei University, Tokyo \\ E-mail: samankalu@hotmail.com
}

\begin{abstract}
The study reported in this paper examines how the TQM implementation efforts of a Sri Lankan public hospital were accomplished alongside an attempt to change its culture. The study revealed that the change in the cultural values of the hospital occurred as a result of the implementation of Japanese 5S-based TQM activities. However, it was the democratic leadership and communication of the CEO that functioned as the intermediating factor for this change. The CEO's personal values created and maintained an ideal type communication with the different employee categories for the successful integration of TQM activities. Further, the study revealed that the selected national cultural values of Sri Lanka did not constrain the democratic leadership values of the CEO.
\end{abstract}

Keywords: democratic communication by the CEO, Japanese 5S-based TQM activities, Sri Lankan cultural values, Sri Lankan public hospitals, TQM implementation

\section{Introduction}

During the last two decades, successive governments of Sri Lanka have attempted to fulfill their obligations by improving the health care provisions in the preventive and curative sectors. In this regard, the preventive health care service areas were reformed to serve more people. Many of the existing hospitals in remote areas were upgraded. With regard to the public health care sector, the reformation process began in 1994. These reforms allowed for the establishment of District General Hospitals in each district. The hospitals were aimed at providing basic specialized services. Further, the training of health personnel was intensified, and medical as well as paramedical staff members were appointed to many hospitals. Moreover, the intensive care and laboratory facilities were expanded with appropriate technology. 


\section{KASP Kaluarachchi}

However, despite all these commitments of the Ministry of Health, the following significant deficiencies still prevail in the services provided by the public hospitals in Sri Lanka.

- The services provided by some hospitals are not focused on the expectations of the patients.

- The services provided by the hospitals are not attractively packaged or presented to the people.

- Many of the hospitals ignore the non-health expectations of the people such as basic human needs, dignity, kindness and compassion, proper communication with the patients and their relatives, and prompt attention in the emergency care unit.

- There are numerous complaints about the death and/or disability of a patient due to inappropriate care and negligence.

Although the hospitals do provide valuable services for the public, the services are not well recognized by the people. However, some public hospitals have taken the initiative to enhance the quality of their services by improving infrastructure, reviewing monthly performance, preparing manuals and guidelines, initiating productivity improvement programs, and so on (Ministry of Health, Sri Lanka, 2005).

The major inadequacies in the services provided by public hospitals in Sri Lanka primarily stem from the administration style that follows a set of rigid rules and regulations imposed by the Ministry of Health. Further, the hospital staff is allocated by the central and/or provincial ministries of health; thus, the hospital managers rarely enjoy the authority to recruit personnel. Furthermore, and as a result, shortages of staff exist in many employment positions. Moreover, the remuneration packages are also unable to stimulate improvements in the service quality of the hospitals. In general, the work environment also appears to be unsatisfactory for the employees (Ministry of Health, Sri Lanka, \& Japan International Cooperation Agency, 2003).

The abovementioned service quality issues predominant in Sri Lankan public hospitals is further addressed in this paper, alongside the national cultural values of Sri Lanka. This is because it is these values that in most cases function as constraints to innovation efforts such as the TQM ${ }^{1}$ implementation efforts of Sri Lankan public hospitals.

Nanayakkara (1999) examined the relationship between culture and management in Sri Lanka from a cultural perspective in order to understand the managerial behaviors of Sri Lankan organizations. To represent the relationship between culture and managerial behaviors, the author identified dependence, lack of self-confidence, acceptance of status quo, work as a means, respect for authority, and lack of system and perfection as the major cultural values of Sri Lanka.

Studying new management systems (NMS), some scholars (Samarathunga \& Bennington, 2002;

\footnotetext{
${ }^{1} \mathrm{TQM}$ is an acronym for total quality management.
} 


\section{Successful TQM implementation in Sri Lankan public hospitals}

Gunathunga, 2003; Wickramasinghe \& Hopper, 2005; Wickramasinghe, Hopper, \& Rathnasiri, 2004) found that the political bureaucracy and poor administrative setup of public sector organizations in Sri Lanka have discouraged the implementation of NMS within those organizations. Hence, NMS programs have simply become technically, rather than managerially, meaningful to the organizations.

As suggested in Opatha (2001), the politicization and multiplicity of labor unions have become the two major irritants with respect to the creation and maintenance of good industrial relations within organizations in Sri Lanka. Consequently, on the one hand, labor unions' ability to accomplish the objectives of their members/workers through effective relations with managers is limited, and on the other hand, managers find it difficult to manage the organizations by making strategic decisions such as automation, rationalization, technological changes, etc.

Although the abovementioned organizational and national culture backgrounds of Sri Lanka function as constraints to the innovation efforts of the Sri Lankan public hospitals, some public hospitals have been well recognized by the public for their responsive services, achieved through the successful implementation of new quality management methods. As the main example, a Sri Lankan public hospital, namely, the Castle Street Hospital for Women, which practices Japanese 5S-based TQM activities, has won several quality awards for being more responsive to the public demands.

Therefore, based on the above, this study was motivated by the need to examine the TQM implementation efforts of the said hospital within its cultural setup. However, it is understood that modernization efforts such as TQM implementation need to be studied from a larger perspective, because it is regarded as a historically and culturally constructed phenomenon. Moreover, such efforts lead to changes in the culture of the organization.

According to the study, the attempt to change the culture of the hospital at stake by means of TQM rationality is considered to be a challenge. The challenge is mainly because of the different subcultures $^{2}$ (i.e., different employee categories) that exist within an organization, which may not necessarily be easily integrated into TQM implementation activities.

Thus, the purpose of the study reported in this paper was to examine how TQM implementation efforts of the abovementioned Sri Lankan public hospital have been accomplished alongside the attempt to change its culture.

\footnotetext{
2 The subcultures of the hospital were identified at its managerial and non-managerial employee levels. The managerial employee level of the hospital was identified with its Director/CEO (senior management) and divisional heads (middle management). The divisional heads comprised the Senior Medical Officer, Matrons, Administrative Officer, Accountant, and Chief Pharmacist. Presently, there are three matrons in the hospital. The non-managerial employee level was identified with the doctors, nursing sisters and nurses, paramedical staff, midwifery staff, clerical staff, and support staff. All these different employee categories were identified as different subculture groups of the hospital that may differently affect the TQM implementation process.
} 
Table 1. Timeline of the TQM implementation process at CSHW

\begin{tabular}{|c|c|c|c|}
\hline Year & Activities/Events & Classification of each activity & $\begin{array}{l}\text { Names used } \\
\text { for analysis }\end{array}$ \\
\hline \multirow[t]{2}{*}{2000} & Implementation of the $5 \mathrm{~S}$ program & Organization development & OD1 \\
\hline & Implementation of kaizen activities & Organization development & OD2 \\
\hline \multirow[t]{9}{*}{2001} & $\begin{array}{l}\text { Training of divisional heads in productivity } \\
\text { improvement }\end{array}$ & Staff training & ST1 \\
\hline & $\begin{array}{l}\text { Training of clerical and support staffs in } \\
\text { productivity improvement }\end{array}$ & Staff training & ST2 \\
\hline & Renovation of wards & Infrastructure development & ID1 \\
\hline & Improvement of all quarters & Infrastructure development & ID2 \\
\hline & Supply of surgical hospital furniture & Medical supplies & MS1 \\
\hline & Renovation of Labor Rooms A and B & Infrastructure development & ID3 \\
\hline & $\begin{array}{l}\text { Publication of the Quarterly Statistical Bulletin } \\
\text { and Annual Report }\end{array}$ & Patient admission and transfer & PAT1 \\
\hline & Organization of the Health Information Unit & Infection control activities & ICA1 \\
\hline & $\begin{array}{l}\text { Training of clerical and support staffs in public } \\
\text { relations and office management }\end{array}$ & Staff training & ST3 \\
\hline \multirow[t]{11}{*}{2002} & Construction of Labor Room C & Infrastructure development & ID4 \\
\hline & Renovation of Labor Rooms A and B & Infrastructure development & ID5 \\
\hline & Improvement of offices and stores & Infrastructure development & ID6 \\
\hline & $\begin{array}{l}\text { Location management training for nursing and } \\
\text { midwifery staffs }\end{array}$ & Staff training & ST4 \\
\hline & Introduction of $10 \mathrm{CTG}$ machines & Diagnostic activities & DA1 \\
\hline & Improvement of the Neonatology Unit & Infection control activities & ICA2 \\
\hline & Improvement of the OPD & Infrastructure development & ID7 \\
\hline & Improvement of record keeping & Patient admission and transfer & PAT2 \\
\hline & Development of tools for record keeping & Patient admission and transfer & PAT3 \\
\hline & Establishment of a performance appraisal system & Employee relations & ER1 \\
\hline & New computers for clerical staff & Infrastructure development & ID8 \\
\hline \multirow[t]{5}{*}{2003} & Introduction of laparoscopy and colposcopy & Diagnostic activities & DA2 \\
\hline & Improvement of kitchen & Infrastructure development & ID9 \\
\hline & Training of divisional heads and doctors in TQM & Staff training & ST5 \\
\hline & New equipment for the Operating Theatre & Diagnostic activities & DA3 \\
\hline & Improvement of the Intensive Care Unit & Infrastructure development & ID10 \\
\hline \multirow[t]{4}{*}{2004} & Training of support staff in infection control & Staff training & ST6 \\
\hline & Improvement of the laboratory & Diagnostic activities & DA4 \\
\hline & $\begin{array}{l}\text { Training of the nursing staff in neonatal and } \\
\text { intensive care }\end{array}$ & Staff training & ST7 \\
\hline & $\begin{array}{l}\text { Installation of a computerized information } \\
\text { system }\end{array}$ & Infrastructure development & ID11 \\
\hline & $\begin{array}{l}\text { analytical purpose, each historical activity was clas } \\
\text { Moreover, the activities were organized according } \\
\text { ted. }\end{array}$ & fied and named under clinica & $\begin{array}{l}\text { QM-orientec } \\
\text { were }\end{array}$ \\
\hline
\end{tabular}

\section{The study of a Sri Lankan public}

\section{hospital}

The Castle Street Hospital for Women (hereafter CSHW) is a public maternity hospital in Sri Lanka. It was established in 1950 and presently functions as the largest maternity hospital in Sri Lanka with a capacity of 846 employees and 450 beds. It provides maternal, gynecological, and neonatal care services. The number of deliveries every year ranges between 16,000 and 18,000 , with an average of $27 \%$ cesarean deliveries. 
Figure 1. Service outcomes of CSHW

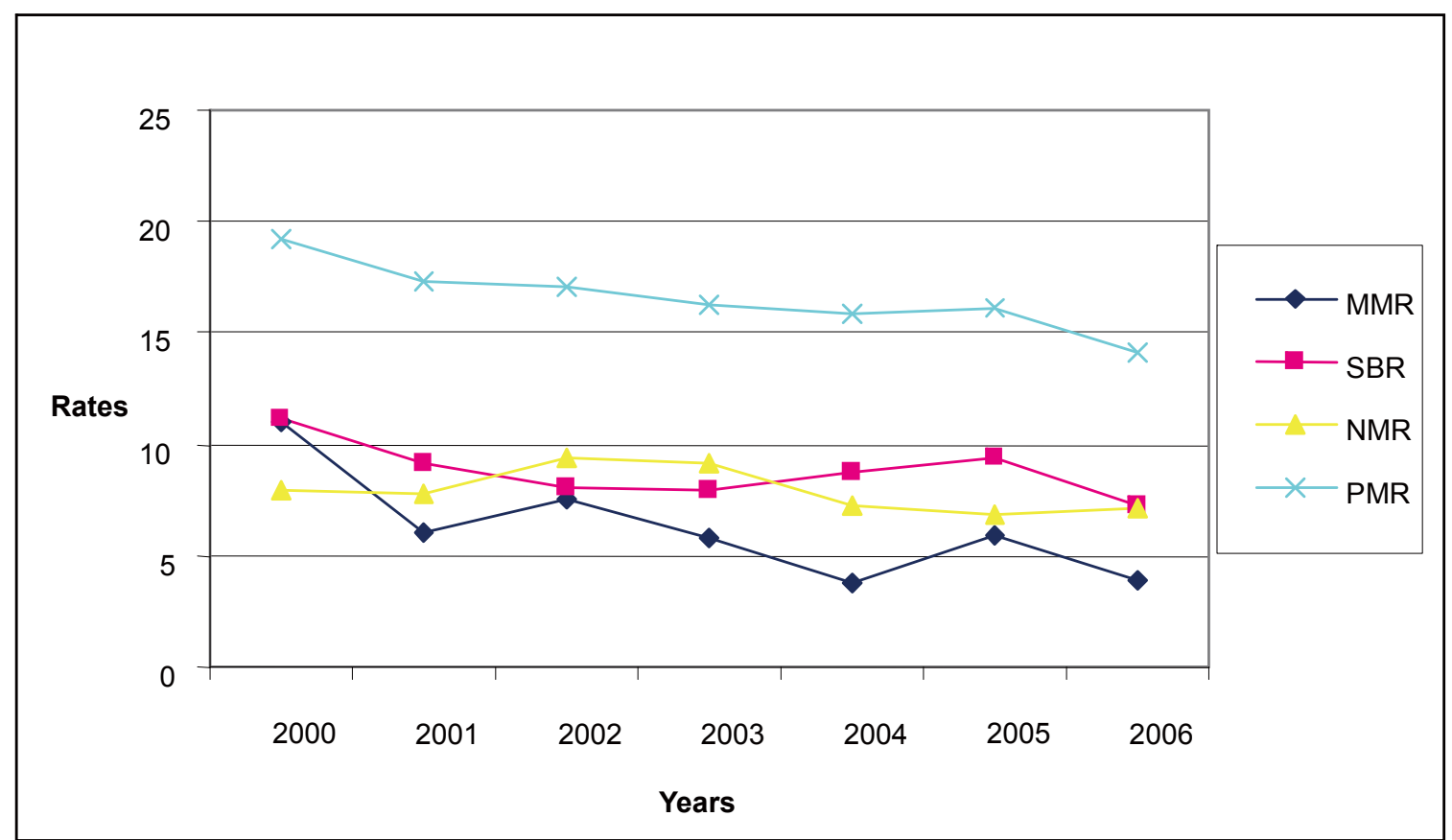

Notes: $\mathrm{MMR}=$ maternal mortality rate; $\mathrm{SBR}=$ stillbirth rate; $\mathrm{NMR}=$ neonatal mortality rate; and $\mathrm{PMR}=$ perinatal mortality rate. MMR/10,000 live births; SBR/1,000 total births; NMR/1,000 live births; PMR/1,000 total births (total births $=$ live births + stillbirths). The data on MMR, SBR, NMR, and PMR were unavailable for the period before 2000 due to the lack of maintenance of proper records in the hospital. Therefore, a review of the service outcome for the period before 2000 could not be done. No other major internal factors of the hospital that could have specially affected its service outcomes were noticed during the considered period. No major improvements or changes in the public health care sector in Sri Lanka that could have specially affected the service outcome of the hospital were noticed during the considered period.

Source: Castle Street Hospital for Women (2007).

During the first 50 years of its service, CSHW functioned as a governmental/public hospital implementing traditional administrative systems and measures. It did not focus on adopting NMS to deliver better care and services to the public. Hence, the major deficiencies in the services provided by public hospitals in Sri Lanka (as mentioned in the first section of the paper) were common to CSHW as well. Thus, during the first 50 years of service, the culture of CSHW was regarded as being non-integral with respect to the improvement of its service quality. The non-integral culture $e^{3}$ of the hospital was

\footnotetext{
${ }^{3}$ Since this paper deals with the issue of integrating the subcultures of CSHW with its TQM implementation efforts, the process of its cultural change is conceptualized as a change that occurs from a non-integral status to an integral status. In other words, the process of the change is conceptualized as the change from a non-integral culture to an integral culture. This was mainly followed by a value-based terminology. Hence, the term "integral culture" used in this paper should be understood as a shared culture towards TQM implementation. The opposite term "non-integral culture" should be understood as a non-shared culture towards TQM implementation. The paper operationalizes non-integral culture with individualism, risk-aversion, and short-term orientation. Contrarily, integral culture is operationalized with teamwork, risk recognition with respect to change, and long-term orientation. This has been further illustrated in Figure 2.
} 


\section{KASP Kaluarachchi}

observed in its (1) individualistic work orientation,

(2) risk-aversion with respect to change, (3) short-term orientation, and (4) visibly poor display of improved service facilities.

However, in January 2000, a new director, ${ }^{4}$ namely, Dr. Karandagoda, was appointed as the $\mathrm{CEO}^{5}$ of the hospital. A few months after assuming his duties, Dr. Karandagoda was surprised by the high maternal mortality rate of the hospital. He further noted that in most cases, the high mortality was due to the infections spread within the hospital or due to other inappropriate post-treatment care. $\mathrm{He}$ concluded that the deaths could have been prevented by the collective effort of the staff.

Hence, with the objective of reducing the mortality rate, the new CEO (Dr. Karandagoda) began to introduce Japanese $5 \mathrm{~S}^{6}$-based $\mathrm{TQM}$ activities in April $2000^{7}$ as an effort toward the modernization of the hospital. A timeline of the implementation of TQM activities is presented in Table 1. The activities were recognized as the historical activities or events that took place during

\footnotetext{
${ }^{4}$ In this paper, the terms "director" and "CEO" have been used interchangeably.

${ }^{5} \mathrm{CEO}$ is an acronym for chief executive officer.

${ }^{6}$ Japanese $5 \mathrm{~S}$ denotes the following five Japanese words seiri (tidiness), seiton (orderliness), seiso (cleanliness), seiketsu (standardization), and shitsuke (training and self-discipline) that collectively form the foundation of an organization methodology.

7 The introduction of Japanese 5S-based TQM activities in the hospital forms the starting point of TQM implementation in Sri Lankan public hospitals. After the successful TQM implementation in this hospital, the Ministry of Health established a section called the "Quality Secretariat," which is responsible for the cultivation and development of a quality-oriented culture in public hospitals. Presently, the Secretariat runs the National Quality Assurance Program (NQAP) for tertiary hospitals in Sri Lanka.
}

the TQM implementation at CSHW since the new CEO's appointment.

The implementation of Japanese 5S-based TQM activities at CSHW not only reduced the mortality rate, which was a result of the reduction in infection rates, but also reduced the consumption of antibiotics, resulting from the decline of nosocomial infections and different kinds of waste like space, transport, movement time, and waiting time. Figure 1 illustrates the service outcomes of the hospital for the period after the implementation of 5S-based TQM activities.

The data provided in Figure 1 indicates that CSHW gradually improved its service outcome/performance (i.e., reduction of MMR, SBR, NMR, and PMR). For example, from 2000 to 2006, it reduced MMR from 11.0 to 3.9 , which is approximately a 64\% improvement in service performance. During the same period, it was able to reduce SBR from 11.2 to 7.3 , which is approximately a 35\% improvement in service performance. Moreover, both NMR and PMR were reduced from 7.9 to 7.1 and 19.2 to 14.1 , respectively, which constitute a $10 \%$ and $26 \%$ improvement in service performance.

Table 2 associates the service outcomes of CSHW with its historical activities. The activities implemented during the respective years have contributed to improve the service outcomes (i.e., reduced MMR, SBR, NMR, and PMR). The historical activities of the hospital are related to its clinical and TQM-oriented activities. The clinical 


\section{Successful TQM implementation in Sri Lankan public hospitals}

Table 2. Linking CSHW's service outcome with its history of TQM implementation

\begin{tabular}{lll}
\hline Year & Historical activities & Reduced rates \\
\hline 2000 & OD1, OD2 & MMR, SBR, NMR, PMR \\
2001 & ST1, ST2, ID1, ID2, MS1, ID3, PAT1, ICA1, ST3 & SBR, PMR \\
2002 & ID4, ID5, ID6, ST4, DA1, ICA2, ID7, PAT2, PAT3, & MMR, SBR, NMR, PMR \\
& ER1, ID8 & MMR, NMR, PMR \\
2003 & DA2, ID9, ST5, DA3, ID10 & NMR, PMR \\
2004 & ST6, DA4, ST7, ID11 & \\
Notes: OD1, OD2, ST1, etc. refer to the historical activities & implemented in the respective \\
years. Refer to Table 1 and Figure 1 for the meaning of the abbreviations. \\
Sources: Created based on Table 1 and Figure 1.
\end{tabular}

Table 3. Service outcome rates of CSHW in comparison to the national figures of Sri Lanka

\begin{tabular}{|c|c|c|c|c|c|c|c|c|c|c|c|c|}
\hline \multicolumn{13}{|c|}{ Rates } \\
\hline \multirow[b]{2}{*}{ Year } & \multicolumn{3}{|c|}{ MMR } & \multicolumn{3}{|c|}{ SBR } & \multicolumn{3}{|c|}{ NMR } & \multicolumn{3}{|c|}{ PMR } \\
\hline & CSHW & SL & $+1-$ & CSHW & SL & $+1-$ & CSHW & SL & $+1-$ & CSHW & SL & $+1-$ \\
\hline 2000 & 11.0 & 5.6 & $(-5.4)$ & 11.2 & 23.7 & $(+12.5)$ & 7.9 & 12.8 & $(+4.9)$ & 19.2 & 32.0 & $(+12.8)$ \\
\hline 2001 & 6.0 & 4.7 & $(-1.3)$ & 9.1 & 22.9 & $(+13.8)$ & 7.8 & 12.7 & $(+4.9)$ & 17.3 & 32.6 & $(+15.3)$ \\
\hline 2002 & 7.5 & 5.3 & $(-2.2)$ & 8.1 & 19.1 & $(+11.0)$ & 9.4 & 10.6 & $(+1.2)$ & 17.1 & 26.2 & $(+9.1)$ \\
\hline 2003 & 5.8 & 4.3 & $(-1.5)$ & 7.9 & 17.1 & $(+9.2)$ & 9.2 & 9.5 & $(+0.3)$ & 16.2 & 24.4 & $(+8.2)$ \\
\hline 2004 & 3.8 & 3.8 & $(0.0)$ & 8.8 & - & - & 7.3 & 8.0 & $(+0.7)$ & 15.9 & - & - \\
\hline 2005 & 5.9 & 4.4 & $(-1.5)$ & 9.4 & - & - & 6.8 & 7.7 & $(+0.9)$ & 16.1 & - & - \\
\hline 2006 & 3.9 & 3.9 & $(0.0)$ & 7.3 & - & - & 7.1 & - & - & 14.1 & - & - \\
\hline
\end{tabular}

Notes: $\mathrm{MMR}=$ maternal mortality rate; $\mathrm{SBR}=$ stillbirth rate; $\mathrm{NMR}=$ neonatal mortality rate; and PMR $=$ perinatal mortality rate. SL refers to Sri Lanka. Further, the figures shown in the $+/-$ column were arrived at by deducting the service outcome rates of CSHW from the relevant national figures of Sri Lanka for each year. The bolded figures depict how the service outcome rates of CSHW have succeeded the relevant national figures of Sri Lanka. The national figures related to SBR and PMR from 2004 to 2006 and NMR for 2006 were unavailable. Therefore, the comparative analysis for those years could not be done.

Sources: Castle Street Hospital for Women (2007); Family Health Bureau (2006, 2009); Researcher's interview transcripts.

activities were identified as infection control activities (i.e., ICA1, ICA2); diagnostic activities (i.e., DA1, DA2, DA3, DA4); and patient admission and transfer (i.e., PAT1, PAT2, PAT3). They function as the direct or primary activities that contribute to enhance service outcomes. The TQM-oriented activities were identified as medical supplies (i.e., MS1); employee relations (i.e., ER1); staff training (i.e., ST1, ST2, ST3, ST4, ST5, ST6, ST7); infrastructure development (i.e., ID1, ID2, ID3, ID4, ID5, ID6, ID7, ID8, ID9, ID10, ID11); and organization development (i.e., OD1, OD2). These function as indirect or secondary or supportive activities that contribute to the improvement of the service outcomes. Further, Table 3 presents the service outcome rates of the hospital in comparison to the national figures of Sri Lanka.

The comparative figures shown in Table 3 indicate that after the implementation of Japanese 5S-based TQM activities in 2000, CSHW gradually overcame the negative growth of MMR. Moreover, CSHW was able to meet the national figures of MMR: 3.8 and 3.9 in 2004 and 2006, respectively. This can be regarded as a substantial improvement in its service performance following the implementation of Japanese 5S-based TQM 


\section{KASP Kaluarachchi}

Table 4. Quality awards won by CSHW

\begin{tabular}{ll}
\hline Year & Awards \\
\hline 2001 & Akimoto 5S Award (Best 5S Implementer in \\
& Service Sector) \\
& National Productivity Award (Service Sector) \\
2002 & Kaizen Award Runner-up \\
& $\begin{array}{l}\text { Sri Lanka National Quality Merit Award } \\
\text { (Large-Scale Service Sector) } \\
\text { National Productivity Gold Award (Service } \\
\text { Sector) }\end{array}$ \\
\hline
\end{tabular}

activities. With regard to SBR, NMR, and PMR, the hospital performed better than the corresponding national figures for all the years in consideration (see the bolded figures in Table 3). This is a remarkable improvement in the service performance of CSHW after the implementation of Japanese 5S-based TQM activities. Consequently, CSHW was able to win several quality awards for being more responsive to public demands through successful TQM implementation. Table 4 presents the quality awards won by the hospital.

\section{2-1. Japanese 5S-based TQM activities}

Similar to many other large-scale organizations (e.g., large-scale manufacturing organizations), $\mathrm{CSHW}$ is also a large-scale maternal hospital, consisting of different categories of employees who treat patients by using different kinds of equipment and procedures. In addition, there are large amounts of unwanted items, such as clinical waste, that are collected in the hospital premises. This increases the risk of associated infections within the hospital. Mostly, disorganized situations endanger the lives of patients and employees. Thus, the new
CEO introduced Japanese $5 \mathrm{~S}$ concepts in order to organize the hospital and create a pleasant and safe environment for both patents and employees.

The 5S program was introduced as a basis for improvement towards performance excellence (i.e., TQM). The key benefits that CSHW gained through the implementation of $5 \mathrm{~S}$ concepts were less waste, less waiting time, less human error, less accidents, and reduced deaths and disabilities of patients. The 5S program of CSHW has been briefly explained below.

- Tidiness (Seiri): This deals with the systematic removal of unwanted items. It includes waste disposal by using a color code and arranging central unwanted item stores to collect and repair the unwanted items and medical equipment according to the government rules and regulations. Further, the stores also help in eliminating unwanted building materials, unplanned building structures, and trees, and in organizing used documents and files according to the audit procedures.

- Orderliness (Seiton): This involves the systematic arrangement of items, areas, and staff to facilitate use. The items are placed such that they are easy to see, easy to pick up, and easy to return. In keeping with this, CSHW has systematically arranged its service areas, equipment, emergency areas, and staff. In particularly, CSHW has organized the Central Sterile and Linen Supplies Divisions with special care. Further, the General and Medical Supplies 


\section{Successful TQM implementation in Sri Lankan public hospitals}

Stores have also been updated and arranged systematically. Moreover, the hospital has addressed a wide range of activities such as the basic needs of patients, emergency care, supplies and equipment, and identification of directions to places and areas with specific indicators and activities.

- Cleanliness (Seiso): This refers to systematic and meaningful cleaning. CSHW has implemented a preplanned cleaning program. Further, a register is maintained for the cleaning of floors and toilets and the oiling and servicing of trolleys. Preventive maintenance of equipment is conducted regularly.

-Standardization (Seiketsu): Under this practice, what is being organized and implemented is recorded and standards are prepared to make supervision and monitoring more comfortable. Further, some checklists and monitoring indicators are prepared for recommendation.

- Training and self-discipline (Shitsuke): In the hospital, both introductory and in-service trainings are carried out to improve the staff's knowledge of the $5 \mathrm{~S}$ concepts. Further, the staff is self-disciplined to continue the practice of $5 \mathrm{~S}$.

Overall, 5S implementation in the hospital has fulfilled all the requirements of safety. The hospital uses some safety measures in the form of safety sign belts (black and yellow strips) at high-risk areas; safety signs; fire extinguishers; concealment of risky pits; removal of dilapidated buildings and dangerous tools and items that can harm the lives of patients and employees; and development of checklists to avoid mistakes during medical and surgical procedures.

In addition, it utilizes safety tools such as red tags, alignment, numbering, labeling, zones, isles, name boards, sign boards, safety signs, street lines, checklists and stickers, instructions and guidelines, and visual controls. The visual controls have been developed using locally and internationally accepted color codes. For example, black is used for general items, areas, and waste; yellow is used for infected areas and waste; red is used for anything negative, urgent, dirty, un-sterile, and of high risk; blue is used for anything positive, clean, and sterile; and green is used for safe areas. Following the implementation of the 5S program, the hospital has become orderly, clean, and pleasant, with a sense of quality.

Furthermore, based on the $5 \mathrm{~S}$ program, CSHW adopted a step-by-step approach to improve its systems by practicing TQM concepts. This was to satisfy the needs and expectations of patients and employees. By conducting customer satisfaction surveys, it improved the basic needs and counter services at the front line. Moreover, by developing leadership at top, middle, and operational levels, it used a systematic approach to performance reviews and human resource development and deployment. In addition, it carries out in-service training programs for its employees, depending on the service needs.

In its process of TQM implementation, CSHW 


\section{KASP Kaluarachchi}

has been practicing kaizen concepts for continuous improvement. This requires the participation of all employees on a daily basis. The kaizen activities have contributed in many aspects such as the simplification of processes; reduction of different kinds of waste like space, transport and movement time, and waiting time; minimization of storage; improvement in the work efficiency of vehicles and machinery; and improvement in the supply system. Moreover, they have ensured employee participation in the analysis of problems and incidents and the determining of solutions. CSHW has adopted kaizen activities in the form of work improvement teams, a suggestion scheme, just-in-time, total productivity maintenance, and mistake proofing.

Work improvement teams (WIT) have been introduced as an alternative to the quality circles (QC). In comparison with QC, a WIT is more informal, and it does not involve considerable scientific analysis. Hence, a WIT provides different kinds of employees with an increased opportunity to participate in quality management activities. A WIT of CSHW consists of a small group of 6-12 employees, who belong to a particular division. For example, the WIT of the Nursing Division consists of matrons, nursing sisters, nurses, and midwives. Likewise, other divisions have their own WITs. WITs have been appropriately named. They include a chairman, a secretary, and a treasurer. The WIT members gather during leisure hours on a monthly or fortnightly basis to discuss problems, shortcomings, and possible improvements in their relevant divisions. When problems arise in relation to other divisions, they call a member from that WIT to discuss the issue. Each month, the WIT leaders meet the CEO to discuss cross-functional problems and to obtain his support.

The suggestion scheme (SS) has been implemented through external customers (i.e., patients, their relatives, and other visitors) and internal customers (i.e., employees). CSHW has placed suggestion boxes at selected locations. Once a week, the suggestions are collected and recorded. The employees can provide their suggestions in these forms as well as at the WIT meetings. The suggestions received by post and those appearing in the media are also considered. The suggestions of patients are also taken at the time of discharge by means of suggestion forms. Further, customer satisfaction surveys also provide valuable suggestions of the patients. All suggestions are discussed at the Monthly Steering Committee and Management Committee meetings. The management provides feedback to the relevant parties appreciating their suggestions.

The concept of just-in-time (JIT) or lean productivity has been applied in the hospital to minimize storage and to ensure a timely supply of different materials to the working areas. Any item that is supplied centrally and periodically should not be stored in excess in the wards and divisions. The central stores supply stocks by assessing the 


\section{Successful TQM implementation in Sri Lankan public hospitals}

statistics. Any unwanted item wasting away in the workplaces is removed to a centrally located unwanted item store for disposal and/or repair. The items collected that are suitable for use are redistributed to other divisions and/or other hospitals.

Under the concept of total productivity maintenance (TPM), the hospital has a maintenance unit and a calendar for the preventive maintenance of equipment, machinery, vehicles, utility trolleys, etc. Preventive maintenance checklists and guidelines have been displayed at the site of the equipment. All equipment has a display sticker to identify its model and price as well as the contact details of the maintenance agents. For every equipment and machine, there is a "personal file."

With respect to mistake proofing (MP), CSHW maintains a mistake identification register to record the mistakes in medical, nursing, and general procedures. The mistakes are discussed at the WIT meetings and the Monthly Management Committee meetings in order to determine the appropriate action. Due recognition is given for infection control activities, and every ward maintains an Infection Identification Register. Death and Near-Death Reviews comprise the essential activities of MP.

\section{2-2. TQM implementation process}

The implementation of TQM activities at CSHW was a three-phase process: (1) introductory phase, (2) application phase, and (3) maintenance phase. The introductory phase comprised of training the trainers and employees and developing audio-visual materials to ease the understanding of 5S and TQM concepts. ${ }^{8}$ The program for training the trainers was targeted at the teaching units of the nursing and middle-level grades. The employee training programs covered topics such as introduction to quality, $5 \mathrm{~S}$ and productivity concepts, TQM, leadership, public relations and communication skills, and staff commitment toward responsive maternal care. A video film was shown to educate the employees on quality improvement and responsive health care. In addition, employees were instructed on the concepts of 5S and TQM by means of poster displays and other visuals aids.

The application phase involved three specific steps. The first step was to introduce Japanese $5 \mathrm{~S}$ practices. Some productivity concepts were introduced in the second step. The third step was to introduce the concepts of TQM. This phase involved the determining of kaizen practices; preparation of action plans; identification of key areas for improvement; implementation of no cost and urgently needed activities through which employees could be motivated to proceed; establishment of work improvement teams and a steering committee; development of positive attitudes toward change among divisional heads; development of data

\footnotetext{
${ }^{8}$ The training of trainers, training of employees, and other activities that contributed to enhance the quality management knowledge and skills of employees were mainly facilitated by external consultants. External consultants from the Sri Lanka Institute of Development Administration (SLIDA) played a major role in this effort. In fact, Mr. Thilakasiri, a senior consultant at SLIDA, is still popular among the employees.
} 


\section{KASP Kaluarachchi}

collection registers for mistake proofing; organization of audit procedures to dispose accountable documents; development of a rational color code system; introduction of a kaizen suggestion scheme with suggestion boxes, suggestions at discharge, and suggestions by post; execution of periodical competitions among employees to increase motivation toward quality management activities; development of monitoring indicators with a maximum of 15-20 indicators; and appointment of a monitoring team, comprising five senior staff members who are knowledgeable, communicative, and possess leadership qualities.

During the maintenance phase (CSHW is now in this phase), a sound monitoring mechanism was implemented. Periodical reviews were conducted to identify the management development needs and sustain continuous improvement. The monitoring mechanism is simple, rational, convenient, and user-friendly. Monitoring is done on monthly, quarterly, and annual bases, through monitoring indicators, general staff meetings and periodical returns, staff and customer surveys, clinical and management meetings, and the Quarterly Statistical Bulletin and Annual Report. CSHW has implemented managerial functions to address areas such as reception, cleanliness, infection control, human resource management, finance and budget, basic needs of patients, etc. The monitoring indicators are of mainly two types. First, general indicators that have been prepared to address the general management activities and responsive health care service or service quality. Second, specific indicators that have designed to address clinical care or clinical quality matters related to the intensive care unit, operating theatre, labor rooms, laboratories, etc.

\section{2-3. Managing the process of cultural change and the role of leadership}

The ongoing implementation of improvement-oriented activities at CSHW (see Table 1) has contributed toward changing its culture from a non-integral one to an integral one. However, the process of change has been initiated and managed by the democratic leadership of the CEO. The CEO's personal values, namely, teamwork, openness, responsiveness, forgiveness, practical orientation, and continuation, have collectively created and maintained an ideal type of communication with different employee categories (i.e., divisional heads, doctors, nursing sisters and nurses, paramedical staff, midwifery staff, clerical staff, and support staff) for integration with 5S-based TQM activities.

When 5S-based TQM implementation resumed, the CEO was faced with the problem of how to correspond TQM activities with staff awareness and knowledge. In response, the CEO conducted a staff survey to determine staff awareness regarding basic quality management activities. The staff survey covered three major techniques: work improvement teams, inter-group interactions, and general knowledge testing. The results of the staff survey revealed that although the staff members had basic knowledge about quality management, they did not 


\section{Successful TQM implementation in Sri Lankan public hospitals}

have sufficient knowledge about productivity improvement and TQM. Subsequently, the CEO began to organize team-based training programs for the different employee categories.

The employees were targeted as separate groups and were asked to engage in quality management activities. When a particular group displayed poor knowledge about the quality management activities, the group was then instructed by the Health Education Unit. The Health Education Unit rearranged the educational programs to educate such groups. This method is known as "pick[ing] up" quality management activities (CEO). ${ }^{9}$

The CEO's policy towards the TQM implementation process, as described above, did not only follow a top-down approach. Instead, he employed a bottom-up approach through which the staff members were welcome to forward their ideas and suggestions towards the quality management activities.

The staff members' proposals were used to match the quality management activities with their requirements. The new quality management activities were designed and deployed in a simple manner such that the general staff members could understand them easily. As an example, these days, the management is discussing with the staff members on how the midnight reporting system can be further simplified (CEO). ${ }^{10}$

The CEO as the change agent even addressed the forces against the change. In this regard, he realized that direct control of the external forces (e.g., the rigid

\footnotetext{
${ }^{9}$ The CEO of CSHW was interviewed on 17/12/2007 in his office.

${ }^{10}$ The CEO of CSHW was interviewed on 17/12/2007 in his office.
}

administrative setup of the Ministry of Health and other political interventions such as trade union activities) over the change effort would prevent the employees from being involved in the TQM implementation process. Thus, he inferred that achieving successful TQM implementation would be impossible without achieving a consensus among the employees who were the key participants in the TQM implementation process.

With regard to the changes implemented by the management, the employees perceived these changes as opportunities for continuous improvement. On the other hand, with respect to most of the national level or external changes, the employees treated them as threats to their jobs. But, the problems were resolved through continuous discussions with the employees and their unions (CEO). ${ }^{11}$

With regard to participation in TQM activities, the CEO granted the employees autonomy, and only monitored the progress. Most of the time, he encouraged and motivated the employees, even when they made a mistake. This enabled him to continue and sustain the TQM effort along with the high integrity of the employees.

I normally do not punish my employees when they make a mistake. I discuss the matter with them, and then forgive them, asking them not to repeat the same mistake again. In most of the cases, I personally address the issue in order to respond to them without delay. In this way, the issue can be resolved at the very beginning and

\footnotetext{
${ }^{11}$ The CEO of CSHW was interviewed on 17/12/2007 in his office.
} 


\section{KASP Kaluarachchi}

in a friendly manner (CEO). ${ }^{12}$

The commitment of the CEO to implement the TQM activities was clearly evident. By interacting with the employees, he was able to motivate them to cooperate and participate in the change. In fact, the CEO's aim to achieve TQM implementation became a personal aim of the employees who participated in the change, increasing their faith in the superiority of the common purpose. In other words, the high integrity of the employees to work toward a common purpose was the key factor for the success of the implementation. Further, the creation of faith by the CEO has ensured the enduring cooperation of employees with respect to his efforts to bring about change. Hence, the employees' responses to the leadership competency and commitment of the CEO appeared considerably positive in this regard.

The leadership commitment of the director is the main reason for the success of $5 \mathrm{~S}$ implementation in the hospital. Our director played a key role in delegating $5 \mathrm{~S}$ activities to the different kinds of employees and ensuring their active involvement in continuous improvement (Public Relations Assistant). ${ }^{13}$

The commitment and the way in which the director communicated the $5 \mathrm{~S}$ practices in 2000 have had a considerable impact on their present success. He actually used a bottom-up approach which motivated the different employee categories to deal with $5 \mathrm{~S}$. At the very beginning, he educated the staff to remove the unnecessary items from the hospital and to

12 The CEO of CSHW was interviewed on 17/12/2007 in his office.

${ }^{13}$ The Public Relations Assistant of CSHW was interviewed on 17/12/2007 in his office. arrange the things in an orderly manner. Then, time to time, he introduced the other $5 \mathrm{~S}$ principles by motivating the staff continuously (Accountant). ${ }^{14}$

The investigation as a whole helps to understand the salient feature of efficient communication of TQM implementation to the different employee categories of CSHW. It highlights the importance of leadership values, including a practical orientation toward overcoming possible bottlenecks with respect to the implementation. The leadership competency of the CEO was characterized by nothing more than the creation and maintenance of an ideal type of communication with the different categories of employees who were involved in the change effort and possessed high integrity. Therefore, the CEO was able to change the culture of CSHW from a non-integral one to an integral one with positive teamwork, change-oriented risk recognition, and long-term orientation.

Consequently, CSHW was able to improve its service outcome/performance over time. Overall, the service outcome/performance rates have improved and have succeeded the relevant national figures of Sri Lanka. CSHW has been awarded with several quality awards (see Table 4) for being more responsive to the public demands through successful 5S-based TQM implementation. Presently, it functions as a model public hospital in Sri Lanka.

\footnotetext{
${ }^{14}$ The Accountant of CSHW was interviewed on $18 / 12 / 2007$ in her office.
} 


\section{Successful TQM implementation in Sri Lankan public hospitals}

\section{$2-4$. Beyond the national cultural constraints}

It has already been mentioned that the democratic leadership and communication of the CEO of CSHW was the intermediating factor for the cultural change that occurred. The democratic leadership values of the CEO (i.e., teamwork, openness, responsiveness, forgiveness, practical orientation, and continuation) as a whole contributed to the change from non-integral cultural values (i.e., individualism, risk aversion with respect to change, and short-term orientation). Consequently, an integral culture was created by using values such as teamwork, change-oriented risk recognition, and long-term orientation.

Although the selected national cultural values of Sri Lanka, namely, dependence, lack of self confidence, acceptance of status quo, work as a means, respect for authority, lack of system and perfection, political bureaucracy, and poor industrial relations, influenced the non-integral cultural values

Figure 2. Cultural change at CSHW within the national cultural values of Sri Lanka

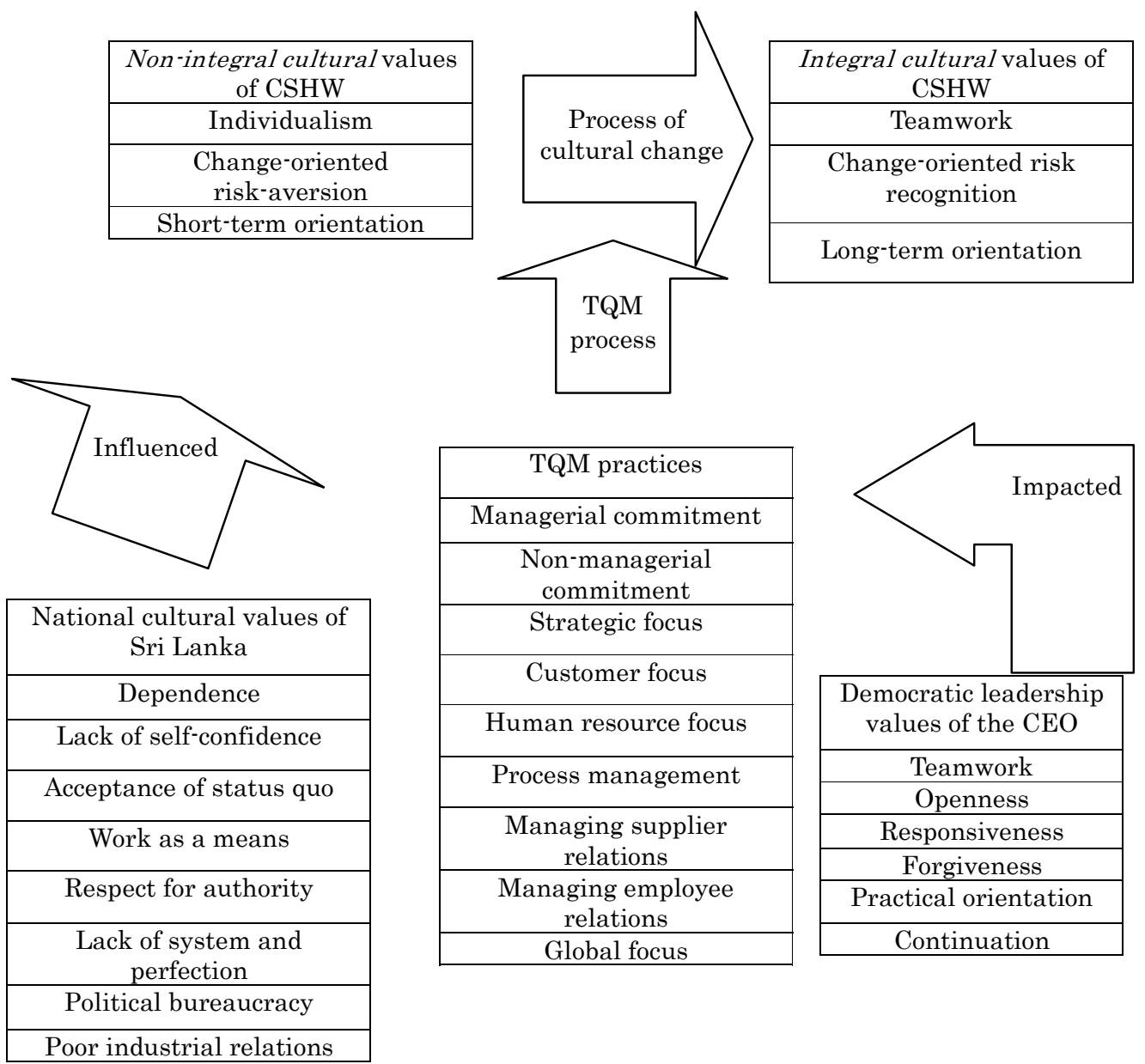

Source: Author 


\section{KASP Kaluarachchi}

of the hospital, they were unable to constrain the democratic leadership values of the CEO. Instead, the democratic leadership values of the CEO impacted the process of cultural change in the hospital.

The director as the CEO initiated and coordinated the quality improvement activities tactfully. He maintained a supportive communication environment, where managerial and non-managerial employees could cooperatively act toward continuous improvement. Even many external forces like political interventions that came from the Ministry were also handled by the director in favor of the hospital (Senior Medical Officer). ${ }^{15}$

The CEO's personal values (i.e., teamwork, openness, responsiveness, forgiveness, practical orientation, and continuation) as a whole created and maintained an ideal type communication with the different categories of employees who were involved in the TQM implementation process and possessed high integrity. Consequently, the CEO was able to change the culture from a non-integral one to an integral one in order to successfully implement 5S-based TQM activities. Thus, the democratic leadership values of the CEO with the TQM practices have intermediated the process of cultural change at the hospital, taking it beyond the national cultural constraints. These relationships have been illustrated in Figure 2.

15 The Senior Medical Officer of CSHW was interviewed on $19 / 12 / 2007$ in the hospital library.

\section{Discussion}

Successful TQM implementation at CSHW revealed one important aspect pertaining to the CEO's personal values, namely, teamwork, openness, responsiveness, forgiveness, practical orientation, and continuation. These values contributed as a whole in the creation and maintenance of an ideal type of communication with different employee categories in order to integrate Japanese 5S-based TQM activities within the organizational boundary. As a result, forces against the change, both internal and external, were overcome. The CEO's bottom-up management approach supported by his democratic leadership and communication style functioned as the intermediating factors with respect to changing the mindset of the employees. Consequently, the employees engaged in 5S-based TQM activities, displaying high integrity. This has served as the core strategy for the successful employment of other strategies for change, such as executing educational and training programs, enhancing employee involvement in decision-making, creating a new organizational culture with small group activities and teamwork, introducing new policies and procedures to reward the employees, and executing evolutionary changes that were enthusiastically accepted by the employees. All these strategies employed by the CEO can be collectively regarded as a successful behavioral or organizational development approach toward change management.

Successful TQM implementation at CSHW has contributed by improving its service 


\section{Successful TQM implementation in Sri Lankan public hospitals}

outcome/performance over time. Most of its service outcome/performance rates have succeeded the relevant national figures of Sri Lanka. Consequently, it has been awarded with several quality awards for being more responsive to the public demands through successful TQM implementation. Presently, it functions as a model public hospital in Sri Lanka.

In comparison to the rigid administrative setup of the other public hospitals in Sri Lanka (Ministry of Health, Sri Lanka, 2005; Ministry of Health, Sri Lanka, \& Japan International Cooperation Agency, 2003), the employees of CSHW did not embrace such rigid organizational structures and thinking, when engaging in 5S-based TQM activities. Moreover, compared to the selected national cultural values of Sri Lanka (Nanayakkara, 1999; Samarathunga \& Bennington, 2002; Gunathunga, 2003; Wickramasinghe \& Hopper, 2005; Wickramasinghe et al., 2004; Opatha, 2001), the employees did not hold on the ingrained schemas that would have prevented them from being able to function using new strategies. Instead, the employees had faith in the superiority of the common shared purpose and regarded participation in the process of change as a personal aim. Thus, based on an analysis of CSHW, it can be argued that communicating with different employee categories using a bottom-up management approach with democratic leadership is vital for the successful integration of a change effort, such as the TQM implementation, within the organizational boundaries of public hospitals in Sri Lanka.

\section{Conclusion}

The purpose of the study reported in this paper was to examine how TQM implementation has been achieved within a Sri Lankan public hospital alongside an attempt to change its core cultural values. The paper concludes the related findings as follows.

The change of culture at the hospital has occurred as a result of its Japanese 5S-based TQM activities that were implemented in 2000 . However, it was the democratic leadership and communication of the CEO that functioned as the intermediating factor for the change from a non-integral culture to an integral culture. The CEO's personal values, namely, teamwork, openness, responsiveness, forgiveness, practical orientation, and continuation, served collectively to create and maintain an ideal type of communication with the different categories of employees (i.e., divisional heads, doctors, nursing sisters and nurses, paramedical staff, midwifery staff, clerical staff, and support staff) who were engaged in 5S-based TQM activities and possessed high integrity. Thus, the CEO's bottom-up management approach supported by his democratic leadership and communication style ensured the ongoing change in the mindset of employees toward the TQM implementation.

Successful TQM implementation in the hospital contributed toward improving its service outcome/performance over time. Most of its service outcome/performance rates succeeded the relevant 


\section{KASP Kaluarachchi}

national figures of Sri Lanka. Consequently, the hospital was awarded with several quality awards for being more responsive to the public demands through successful TQM implementation. Presently, it functions as a model public hospital in Sri Lanka. Thus, the findings reinterpret the previous evidence on public hospitals in Sri Lanka (Ministry of Health, Sri Lanka, 2005; Ministry of Health, Sri Lanka, \& Japan International Cooperation Agency, 2003).

The selected national cultural values of Sri Lanka, i.e., dependence, lack of self confidence, acceptance of status quo, work as a means, respect for authority, lack of system and perfection, political bureaucracy, and poor industrial relations, did not constrain the democratic leadership values of the CEO. On the contrary, the democratic leadership values of the CEO impacted the process of cultural change at the hospital. Consequently, the CEO was able to change the culture of the hospital from a non-integral one to an integral one in order to successfully implement 5S-based TQM activities. Further, the CEO's personal values as a whole created and maintained an ideal type communication with different categories of employees, who were engaged in the TQM implementation process and had high integrity. Hence, the findings reinterpret previous evidence on the national cultural values of Sri Lanka (Nanayakkara, 1999; Samarathunga \& Bennington, 2002; Gunathunga, 2003; Wickramasinghe \& Hopper, 2005; Wickramasinghe et al., 2004; Opatha, 2001).
To overcome the limitations of this single case study, future studies on this subject need to be conducted. Further, comparative studies and survey research, including private hospitals in Sri Lanka, should also be carried out.

\section{Acknowledgments}

The author would like to extend his gratitude to Professors Masao Yokouchi, Yongdo Kim, Noriko Taji, and Tomofumi Amano for their guidance. Further, the author would like to thank all the members of the MMRC research group of the University of Tokyo for their comments on the paper. Last, but not the least, the author would like to express his gratitude toward all the study participants of the Castle Street Hospital for Women for their kind cooperation during the data gathering phase.

\section{References}

Castle Street Hospital for Women. (2006). Action plans, 2006. Colombo: Castle Street Hospital for Women.

Castle Street Hospital for Women. (2007). Annual report, 2006. Colombo: Castle Street Hospital for Women.

Family Health Bureau, Ministry of Health, Sri Lanka. (2006). Annual report on family health in Sri Lanka 2003-2004. Colombo: Family Health Bureau, Ministry of Health, Sri Lanka.

Family Health Bureau, Ministry of Health, Sri Lanka. (2009). Annual report on family health in Sri Lanka 2006-2007. Colombo: Family Health 


\section{Successful TQM implementation in Sri Lankan public hospitals}

Bureau, Ministry of Health, Sri Lanka.

Gunathunga, R. S. (2003). Habermasian way of understanding information systems development in organizations in Sri Lanka. Proceedings from: The Ninth International Conference on Sri Lanka Studies, 28-30 November 2009. Matara, Sri Lanka: Faculty of Management and Finance, University of Ruhuna.

Ministry of Health, Sri Lanka. (2005). National quality assurance program for the health services in Sri Lanka: A practical guide for hospitals. Colombo: Ministry of Health.

Ministry of Health, Sri Lanka, \& Japan International Cooperation Agency. (2003). Master plan study for the strengthening of health systems in the Democratic Socialist Republic of Sri Lanka. Colombo: Pacific Consultants International.

Nanayakkara, G. (1999). Culture and Management in Sri Lanka. Colombo: Postgraduate Institute of Management.

Opatha, H. D. N. P. (2001). Politicization and union multiplicity: Two major irritants to good industrial relations in Sri Lanka. Human Resource Management: Interpretive and Explanatory Papers, $1,10-17$.

Samarathunga, R., \& Bennington, L. (2002). New public management: Challenge for Sri Lanka. Asian Journal of Public Administration, 24(3), 87-109.

Wickramasinghe, D. P., \& Hopper, T. (2005). A cultural political economy of management accounting controls: A case study of a textile mil in a traditional Sinhalese village. Critical Perspectives on Accounting, 16(4), 473

Wickramasinghe, D. P., Hopper, T., \& Rathnasiri, C. (2004). Japanese cost management meets Sri Lankan politics: Disappearance and reappearance of bureaucratic management controls in a privatized utility. Accounting, Auditing \& Accountability Journal, 17(1), 85-120.

[Received October 13, 2009; accepted November 5 2009] 
KASP Kaluarachchi 